\title{
LA 'ENUNCIACIÓN DE OBJETO’ EN CATULO, HORACIO Y MARCIAL
}

Dorde Cuvardic García

Maricela Cerdas Fallas

\section{(9) $\mathbb{P Q \Theta O}$}

Doi: https://doi.org/10.15517/rfl.v46iEspecial.41587

URL: https://revistas.ucr.ac.cr/index.php/filyling/index 



\title{
LA 'ENUNCIACIÓN DE OBJETO’ EN CATULO, HORACIO Y MARCIAL
}

\author{
IT-FICTION IN CATULLUS, HORACE AND MARTIAL
}

\author{
Dorde Cuvardic García \\ Maricela Cerdas Fallas
}

\begin{abstract}
RESUMEN
El presente artículo tiene por objetivo identificar, analizar e interpretar ejemplos de enunciación de objeto en textos de los autores romanos Catulo, Horacio y Marcial. La enunciación de objeto se caracteriza por ofrecer una subjetividad propia, procedente de las cosas, las materias primas, los objetos de la naturaleza o los animales. Se distingue, de esta manera, de la enunciación de las fábulas (donde los animales no son sino transposiciones alegóricas de los intereses y las prácticas humanas) y del relato maravilloso, en el que los objetos intervienen en las acciones humanas (y en ocasiones las enjuician). La enunciación de objeto en la literatura y la cultura grecolatina se puede considerar como un precedente de la it-fiction, subgénero de la literatura satírica occidental de los siglos XVIII y XIX donde monedas, objetos manufacturados y animales que circulaban en la sociedad ofrecían una crítica de la sociedad de su tiempo.
\end{abstract}

Palabras clave: enunciación de objeto; it-fiction; literatura latina; sátira; acto de habla objetual.

\begin{abstract}
This article aims to identify, analyze, and interpret examples of it-fiction in the works of the Roman authors Catullus, Horace and Martial. It-fiction characteristically offers subjectivity that emanates from things, raw materials, objects in nature and animals, thus differentiating itself from object enunciation in fables (where animals are allegorical transpositions of human interests and practices) and fairy tales (where objects intervene in human actions and, on occasion, pass judgement on them). It-fiction in ancient Greek and Latin Literature can be considered a precedent for the sub gender of the same name that surfaced in Western satirical literature in the $18^{\text {th }}$ and $19^{\text {th }}$ centuries, in which objects such as coins, manufactured items and animals that circulated in society offered criticism on that time's society.

Keywords: objectual enunciation; it-fiction; Roman literature; satire; objectual act of speech.
\end{abstract}

Dr. Dorde Cuvardic García. Profesor de la Escuela de Filología, Lingüística y Literatura. Universidad de Costa Rica. Costa Rica. Correo electrónico: dcuvardic@yahoo.es

M. L. Maricela Cerda Fallas. Profesora de la Escuela de Filología, Lingüística y Literatura. Universidad de Costa Rica. Costa Rica. Correo electrónico: maricela.cerdas@ucr.ac.cr

Recepción: 20- 06- 19

Aceptación: 12- 11- 19 
La enunciación de objeto ha existido desde la Antigüedad en la historia de la cultura occidental. Esta práctica consiste en dejar 'hablar' a entidades inanimadas mediante la ficción enunciativa de la primera persona del singular. La literatura siempre se ha ocupado de describir objetos (formas icónicas, al fin y al cabo) que 'emiten' actos de habla verbales: asumen atributos antropomorfos y, particularmente, el pensamiento y la voz. Participan, retóricamente, del procedimiento de la prosopopeya, recurso que fue ampliamente sistematizado por la teoría retórica y literaria de la Antigüedad. Consiste, como bien expresa Mortara,

En representar como personas a seres inanimados o a entidades abstractas. En los sistemas clásicos estaba unida a la alegoría, pero se ha extendido hasta comprender las «humanizaciones», populares y culturales, de los animales en los cuentos, la fabulística, la sátira, en los anecdotarios y en la narrativa en general (2000, p. 301).

Cuando hablamos de prosopopeya, tendemos a asociarla más a la humanización de entidades abstractas y de animales, y no tanto de cosas, situación que limita la amplitud semántica de este recurso. Debemos enfrentarnos a este presupuesto y señalar que la voz de los objetos en la literatura es tan común como la procedente de las abstracciones y de los animales.

Ya hacia el final del Clasicismo, y como subgénero históricamente situado, surgió en el siglo XVIII una literatura, enunciada por objetos y animales, que contó con atributos temáticos y narrativos específicos. Para aludir a este tipo de enunciación, en el ámbito anglosajón ha predominado el concepto de it-fiction, cuya traducción más certera sería, según Ana Peñas, "«ficción de objetos, animales, vegetales y minerales», o «ficción de objetos y seres naturales»»" (2012, p. 499). Estuvo en auge, sobre todo, en los siglos XVIII y XIX, especialmente en Inglaterra, desde una intencionalidad eminentemente satírica (ver la colección de ensayos de Blackwell, 2007) y también han sido identificados, analizados e interpretados ejemplos en el campo literario español del siglo XIX (Peñas, 2011; 2012; 2017). Por lo general, ha quedado asociada a la narrativa, ya hablemos de novelas (de estructura episódica, abierta) o de cuentos. En la mayor parte de estos relatos, los objetos circulan de propietario a propietario por la sociedad, y presencian el descenso en el estatus social de los individuos que los poseen. Por este último motivo, también han sido designados como 'relatos de circulación'. No llegan a ser minificciones, ya que el relato de la circulación del objeto en las distintas esferas sociales exige, por lo menos, la extensión del cuento tradicional.

De entrada proponemos las siguientes preguntas: la enunciación de objeto en la literatura de la Antigüedad, en la que este último ofrezca una subjetividad diferenciada de la humana, ¿se puede considerar como precursora de la it-ficción del siglo XVIII y XIX?; ¿qué similitudes y diferencias expresivas y temáticas encontramos entre la 'enunciación de objeto' en la Antigüedad y la literatura satírica de los siglos XVIII y XIX, dos expresiones literarias que trabajan con la personificación de 'cosas'?

Consideramos que la enunciación de objeto se puede dar en la literatura grecolatina, pero solo cuando se plantee, a nivel ficcional, una subjetividad 'objetual' alejada, aunque sea parcialmente, de la humana, es decir, una subjetividad 'propia' del objeto.

Sobre los animales parlantes de la literatura griega y latina, precisa Ana Peñas (2012, pp. 499-500) que

\footnotetext{
[...] suelen ser en realidad humanos transmutados merced a procesos como la metamorfosis y la metempsicosis. Así, un gallo (aunque en realidad es Pitágoras transmigrado) da lecciones de filosofía práctica al zapatero Micilo en el famoso sueño de Luciano. En el Asno de Oro, la curiosidad y un error llevan a Lucio a convertirse en asno, de modo que, aunque el relato autobiográfico es referido formalmente por el animal (desde la conversión, que se produce avanzado el tercer libro), su conciencia e identidad verdadera responden a la del joven. También los animales son protagonistas en la fábula, un género clásico todavía con fuerte presencia en el siglo XIX.
} 
En otras palabras, se hace referencia a animales que carecen de una subjetividad propia, singular. Sin embargo, aunque en El asno de oro, de Apuleyo (siglo II d. C.), la conciencia de Lucio corresponda a la de un ser humano, las experiencias que protagoniza responden a las que cualquier objeto o animal de carga o doméstico pudiera llegar a tener en su relación, puramente utilitaria, con los seres humanos. Lucio no es un simple portavoz del pensamiento humano, como sucede con las fábulas de animales. En primer lugar, como asno, Lucio es tratado con fines estricta y exclusivamente utilitarios, como cualquier objeto o animal de carga, y racionaliza esta experiencia al comprender que adopta, contra su voluntad, este papel. Termina por entender la realidad social, por decirlo de alguna manera, 'desde la otra orilla'. En segundo lugar, se desarrolla una relación de dominio y propiedad entre el asno (Lucio) y los seres humanos (ladrones, en este caso), que involucra un cambio de propietario. Lucio pasa por varios amos y esta situación convierte a El asno de oro, en cierta medida, en un 'relato de circulación' (es decir, se tematiza la ‘circulación' del asno entre diversos propietarios, como ocurre en la it-fiction del siglo XVIII, que coloca en primer plano la degradación de los objetos en el circuito mercantil del capitalismo).

En sus relaciones con los seres humanos, Lucio es identificado y tratado como un animal. Existe una relación completamente reificada o cosificada entre ambas partes y, lo que es más importante para la instancia lectora, es relatada desde la perspectiva del mismo Lucio. Se percibe como una relación deshumanizada. Lucio toma conciencia de que, al tratarle los seres humanos como un animal de carga, le arrancan toda dignidad humana. Pero -y es uno de los objetivos de esta novela satírica-, la deshumanización, reificación o cosificación también impera entre los mismos seres humanos, dedicados a robarse, a matarse y a esclavizarse entre ellos. Si bien, en la Antigüedad, no se debate la comercialización o mercantilización de la economía a través de la circulación de objetos o animales de compañía sujetos a un valor de cambio (a diferencia de lo que ocurre en la enunciación de objeto de los relatos de la it-fiction de los siglos XVIII y XIX), sí se procede, en el caso específico de El asno de oro, a una crítica de las relaciones de dominiosometimiento típicas de una sociedad esclavista basada en la servidumbre.

No se ofrece la enunciación de objeto -es decir, desde una subjetividad singularizada respecto de la del ser humano-, en los llamados relatos maravillosos. En El asno de oro, diversos objetos hablan, en el 'relato insertado o enmarcado', de la historia de amor entre Amor y Psiquis, a lo largo de las diversas pruebas que, cruelmente, le asigna Venus a la amada de Cupido. La diosa le ordena traer una botella de agua de un manantial-defendido por dos dragones- que surge de la cima de un monte escarpado. Las aguas, tanto para defenderse de Psiquis, que busca extraer líquido del manantial, como para alertarla del peligro de los dragones, lanzan la siguiente advertencia: “¡Aparta!, ¿qué haces? ¡Atención! ¡Ten cuidado! ¡Huye!” (Apuleyo, 1970, p. 172). Asimismo, ante lo que considera como una dificultad infranqueable, que llegue a los infiernos y le pida a Proserpina que guarde un poco de belleza en un cofre (la siguiente prueba de Venus), Psiquis decide arrojarse de una alta torre, pero esta última le aconseja que no lo haga y le ayuda a superar la prueba de la manera más eficaz (pp. 174-176).

Esta misma adscripción de la voz enunciativa del objeto o del animal al discurso de lo maravilloso, la podemos asignar al caballo Janto, el 'de movidos pies', al que Hera había otorgado el don de la voz humana, y que profetiza a Aquiles su inminente muerte en la Ilíada: "Todavía esta vez te traeremos a salvo, vigoroso Aquiles. Pero ya está cerca el día de tu ruina. Y no somos nosotros los culpables, sino el excelso dios y el imperioso destino [...]" (1991, XIX, vv. 404-419). Otro ejemplo se aprecia en el poema épico helenístico Argonáuticas, de Apolonio 
de Rodas (siglo III a. C.), que relata el viaje de Jasón y sus compañeros a la Cólquide para obtener el vellocino de oro. Aquí, un madero insertado por la diosa Atenea en la nave Argos insta a los viajeros a partir (1996, I, v. 523). Hacia el final de la aventura, este madero parlante es el vehículo de la voz de Zeus y les informa a los navegantes de la necesidad de llegar a Eea para ser purificados por la hechicera Circe:

[...] de repente bramó con voz humana el madero parlante de la cóncava nave, que en mitad del estrave ajustara Atenea de una encina de Dodona. A ellos entre tanto un funesto pavor los invadió al escuchar la voz y la grave cólera de Zeus (1996, IV, vv. 585-588).

En los últimos casos mencionados, que pertenecen al mundo maravilloso, la voz objetual no está dotada de una subjetividad singular, propia. Siguiendo la tipología de actantes ofrecida por Vladimir Propp en Morfología del cuento (1985), en el capítulo 6, "Reparto de funciones entre los personajes" -donde el folklorista ruso señala que los objetos pueden actuar como seres vivos-, el agua del manantial (que realiza el acto de habla de la advertencia), la torre (que aconseja), y el madero (que transmite información divina), cumplen las funciones de auxiliares mágicos, o más exactamente, de objetos mágicos.

En cambio, en los epigramas de Marcial, en la poesía de Catulo y en la "Sátira I, 8", de Horacio, los objetos sí se encuentran dotados de una subjetividad propia. Estos casos, que constituyen la parte central del presente artículo, serán analizados a continuación.

\section{La enunciación de objeto en Catulo}

La enunciación de objeto en la poesía se concreta en casos de ficcionalización de la voz poética. En particular, esta máscara enunciativa estuvo presente en la poesía de la Antigüiedad. Cayo Valerio Catulo (s. I a. C.) cuenta con tres poemas cuya voz procede de un narrador en principio inanimado. Desde el orden que ocupan los poemas en el conjunto de su obra, corresponden al número 4, donde habla una nave; el 66, donde el sujeto enunciador es una puerta, y el 67, a cargo de una cabellera femenina, más exactamente, un rizo (sinécdoque de la cabellera, que encontrará amplia fortuna en la historia de la literatura occidental, sobre todo durante el Romanticismo). En cualquiera de estos casos, se procede a la ficcionalización de la instancia enunciativa, alejándonos del yo confesional, equiparable -por simple convención- a la voz del autor, predominante en la historia de la poesía lírica.

En "Diálogo con una puerta" (Poema 67) de Catulo, la enunciación de objeto se emplea en un diálogo dramático entre la voz del poeta, viajero que se detiene en una casa, y la voz de este objeto ${ }^{1}$. ¿Qué simbología reviste este último en la literatura, en este contexto cultural? Como señalan Peiré y Puyuelo (2002, p. 1971), la "puerta en la tradición romana es la guardiana del hogar, el símbolo físico de la tradición familiar y de la estabilidad”. Asimismo, dada su ubicación, es por excelencia el testigo de los amores furtivos que tienen lugar en el hogar que custodia.

$1 \quad$ La voz del poeta se encuentra ficcionalizada bajo el personaje de "El poeta", en la edición de Alianza Editorial. En cambio, en la edición de Cátedra de la obra de Catulo, no se procede a estructurar el poema en términos dramáticos en la traducción al español. 
En palabras de Canter (1920, p. 355), con frecuencia el exclusus amator ${ }^{2}$ (amante rechazado a las puertas de la amada) visualiza este objeto como un obstáculo que actúa voluntariamente contra su amor y por ello, muchas veces lo hace el blanco de sus reproches. En el poema, la misma puerta lo pone en evidencia: "Algunos hay que nada más que topan / con algo no bien hecho / me gritan a la vez: 'Es culpa tuya, puerta"' (Catulo, 2006, vv. 17-20). Por otra parte, se le confiere a este objeto inanimado la potestad de servir de intermediario entre él y su dura puella, es decir, la altiva amada que no atiende a sus llamados. Tiene, en este sentido, un papel paradójico: obstaculiza, por un lado, y ayuda, por el otro. Por esto, a menudo el amante se dirige a la puerta con cantos de súplica (paraclausithyron) que buscan ablandar el corazón de la amada (Canter, 1920, p. 356). El paraclausithyron, tópico procedente de la literatura helenística, designa específicamente el lamento proferido por el amante rechazado ante la puerta de su amada. La puerta del poema, según se infiere de sus palabras, ha sido testigo de las conductas típicas de los enamorados.

En el poema, el sujeto humano le comunica a la puerta que corre un rumor en el que se le acusa de servir bien a su dueño anciano, Balbo, y mal a su joven dueño Cecilio, puesto que no cumplió con su deber de salvaguardar la castidad de la esposa de este último. Fernández Corte (2006, p. 696) plantea que la puerta, en su función de mantener el honor de las casas (igual que los esclavos y las porteras), trata de demostrar a su interlocutor, manteniendo su dignidad, que ha cumplido con su cometido, el de evitar el adulterio en el seno del hogar. Por esta razón, la puerta expresa el acto de habla de la exculpación: "No es [...] culpa mía, aunque digan que es mi culpa, / ni puede decir nadie que he fallado" (Catulo, 2006, vv. 13-16).

La puerta, tal como es utilizada como personaje en este poema, materializa -con un ligero cambio- la frase hecha 'si las paredes hablaran'. Es, finalmente, un testigo de los acontecimientos humanos y de sus pasiones, y busca 'desembarazarse' de la acusación que le plantean: favorecer el adulterio en el hogar. Al perseguir este objetivo, la puerta, más bien, revela irónicamente a su interlocutor una serie de adulterios - del joven Cecilio, de su esposaque tuvieron lugar en la casa bajo su cuidado: "Muchas veces oí a la mujer / que a solas con sus siervas / hablaba en voz muy baja / sobre sus propias infidelidades [...]" (Catulo, 2006, vv. 68-71). Es decir, los seres humanos, y no la puerta, son los únicos 'responsables' de su propia conducta. En palabras de Fernández Corte (2006, p. 697), en vista de este comportamiento, que va más allá de su propia defensa, la puerta, en realidad, se revela como una charlatana y una traidora de la casa confiada a su custodia. En estos términos, la puerta asume una función similar a la adoptada por los objetos de la it-fiction de los siglos XVIII y XIX: la de convertirse en canal expresivo para relatar los acontecimientos y las pasiones humanas, como ocurre, asimismo, con aquellas monedas y objetos vestimentarios (abrigos, etc.) que pasan de propietario en propietario. Es, en otras palabras, un caso de desfamiliarización del acontecer humano, con sus sentimientos, emociones y pasiones contradictorias. Recordemos que el voyeurismo o los secretos de alcoba son temas que se han planteado en la historia de la literatura desde la voz del sujeto subalterno (criado, esclavo y, en el presente caso, el objeto).

Los seres humanos que detentan poder social asumen el mundo de los criados o el objetual como inerte, sin capacidad para monitorear o fiscalizar sus conductas. Desde este

2 El amante desesperado que se ve separado de su amada por el 'obstáculo' de la puerta es un tópico de la poesía helenística adaptado por los romanos. 
punto de partida, la literatura que incorpora la 'enunciación de objeto' trata de atenuar o rebajar la autosuficiencia del sujeto humano, que considera que el mundo de las cosas que le circundan es un espacio ínfimo que debe someterse a sus dictámenes.

Un primer paso para la personificación de un objeto radica en el hecho de que un ser humano, mediante el apóstrofe, se dirija a él como un ser animado y pensante, y así ocurre en la literatura de la Antigüedad (como también en las interpelaciones dirigidas a las entidades de la Naturaleza). Pero un segundo paso para la personificación del objeto consiste en que el objeto reaccione, verbal o conductualmente, a la interpelación verbal del ser humano, o que asuma una voluntad totalmente independiente de las órdenes externas y ofrezca su propia subjetividad, desde unos intereses claramente diferenciados de los humanos, como ocurre con la puerta. Siempre en alusión al poema de Catulo, Fernández Corte (2006, p. 697) considera que este texto no nos ofrece un ejemplo de paraclausithyrón, típico de la elegía amorosa,

Creo que se asemeja más al discurso del esclavo confidente de la comedia que está en todos los secretos de su ama, pues poco más adelante, el discurso adopta este giro. La puerta sabe lo que sabe porque la dueña de la casa no tiene secretos para sus esclavas: ella lo ha oído valiéndose cómicamente de su condición de objeto falsamente inanimado en el que nadie repara.

Disentimos de esta apreciación. Consideramos que esta puerta cumple tanto con el tópico del paraclausithyron (versos 17-20), como con la función del esclavo de la comedia. Enunciativamente hablando, la puerta no carece de subjetividad. Simplemente, como entidad 'subalterna', su discurso emplea los mismos actos de habla que los esclavos y los sirvientes, determinados por su posición social.

La convención del objeto-testigo parlante en el diálogo de la puerta de Catulo, según Fernández Corte (2006, p. 697), es seguida también por Lucio en El asno de oro:

Él asiste como testigo a muchos adulterios gracias a frecuentar un submundo de esclavos, artesanos y ladrones.

La puerta y el asno, ambos objetos sin habla, se asemejan al esclavo-portero, ser socialmente inexistente que sólo adquiere contextura penal al ser acusado por los rumores y tener que organizar su defensa.

Los esclavos, los criados y los objetos no son considerados 'personas', es decir, no son considerados sujetos jurídicos. Nadie pretende recabar su opinión y sus declaraciones no tienen valor legal. La literatura, ante estas situaciones, establece un giro que permite otorgar voz a entidades desprovistas del derecho de respuesta, de derecho a la defensa, ya sea por motivos jurídicos (criados o esclavos) o por motivos ontológicos (objetos).

"La cabellera de Berenice" (Poema 66), de Catulo, es otra pieza que emplea la enunciación de objeto, en este caso, un 'suplemento' del ser humano. Se trata de un poema que tematiza un caso de catasterismo, es decir, la transformación, ya sea de un sujeto humano, de un personaje mitológico, o bien de un objeto inanimado, en aster (estrella), en una constelación o en un fenómeno celeste extraordinario, que a partir de ese momento pasa a formar parte del firmamento. Eratóstenes de Cirene relata algunas de estas metamorfosis como explicación mitológica de las formas de algunas constelaciones. En la descripción de la constelación Leo, se menciona a la reina Berenice II de Egipto, mujer de Ptolomeo III Evergetes, cuya cabellera se convirtió en constelación (1999, p. 56). La reina, tras el regreso de su marido de Asia, consagró a los dioses, en agradecimiento, un rizo de su cabellera. Depositado en un templo, desapareció misteriosamente, pero el astrónomo de la Corte, Conón de Samos (siglo III a. C.), lo identificó con una constelación situada dentro del círculo que forman la Osa Mayor, el Boyero, Virgo y Leo. Antes de que Catulo se hubiera ocupado de este suceso, el poeta alejandrino Calímaco 
(siglo III a. C.) ya lo había relatado, en su caso, desde la primera persona del objeto inanimado, en un poema conservado en forma fragmentaria, donde el rizo proclama: "Cuando miraba la región celeste toda, entre las líneas dibujadas, por donde se deslizan [...] me divisó Conón, allá, en lo alto, el rizo que Berenice a todas las deidades consagrara [...]” (1980, v. 186).

Fernández Corte plantea que Catulo resolvió con mucha pertinencia, a través de la enunciación en primera persona de un objeto inanimado, la problemática de la conversión de un simple rizo en una divinidad, en el marco del catasterismo. Esta práctica fue empleada regularmente por los monarcas alejandrinos y romanos para atribuirse a sí mismos cualidades divinas. La enunciación de objeto "[tiene un propósito utilitario], de acuerdo con el cual la literatura respalda una operación de propaganda ya iniciada por la astronomía en beneficio de la casa reinante" (Fernández Corte, 2006, p. 682). Conón de Samos, astrónomo de la corte de Ptolomeo III Evergetes, según la propia voz del rizo de Berenice, es quien se encarga de certificar la metamorfosis de este último en constelación.

Fernández Corte (2006, p. 682) explica las razones por las que Calímaco (y, por ende, Catulo), decidieron emplear la voz enunciativa objetual: la operación de metamorfosis de un sujeto poderoso (en este caso, el rizo de una reina) en astro o en dios se hace más verosímil cuando se relata como una acción en contra de la voluntad del propio protagonista. Así lo formula la constelación, que todavía, en todo caso, conserva su identidad de rizo femenino. Los sentimientos que expresa provienen de su vida anterior, como parte de la cabellera de Berenice, y no de su actual estado de constelación: "Contra mi voluntad, reina, me fui / de lo alto de tu testa. / Contra mi voluntad, por ti lo juro, / por tu cabeza" (Catulo, 2006, vv. 72-74). De esta manera, "el mechón valora el honor que se le hace, como muestra la solemne obertura, pero no deja de reconocer a lo largo de toda la composición, que él fue desplazado de la cabeza de su dueña en contra de su voluntad" (Fernández Corte, 2006, p. 682). Finalmente, se emplea una convención narrativa típica de la enunciación de objeto de todas las épocas: el objeto se queja ante los lectores de ser una 'entidad' sin la voluntad suficiente como para contrarrestar las decisiones -muchas veces, arbitrarias- del ser humano: “QQué harán unos cabellos / cuando ante el hierro ceden / tantos males?" (Catulo, 2006, vv. 84-86).

Finalmente, en "A su barco" (Poema 4), Catulo nos ofrece otro caso de enunciación de objeto. En este caso, el poeta "crea la ficción de estar recogiendo las palabras de un barco [...] y de traducirlas, en estilo indirecto, a sus propios oyentes" (Fernández Corte, 2006, p. 509). El poema narra las aventuras de la nave, desde que fue construida "en la cumbre del Cítoro" (Catulo, 2006, v. 12), pasando por sus numerosos viajes -por violentos mares y tierras exóticas-, hasta llegar al momento de su retiro: "Ahora envejece / tranquilo y a vosotros se consagra, / gemelos: a ti, Cástor, y a tu hermano" (vv. 27-29). En el poema no se escucha la voz del barco, sino su trasmisión en estilo indirecto desde la voz del narrador: "Este barquito que veis aquí, señores, / afirma ser la nave más veloz / y que nunca ha podido adelantarlo / cualquier otra madera que flotara" (vv. 1-4). Según Fernández Corte (2006, p. 510), el recurso ficcional de objetos que superan con éxito viajes por mar y toman la palabra cuenta con antecedentes en numerosos epigramas griegos. Por lo demás, recordemos que en la Antigüedad es muy común que los escritores describan un objeto inserto en una acción o que relaten el proceso de su manufactura, como bien se encarga de recordar Lessing en su tratado Laocoonte (publicado en 1766), con ejemplos como el cetro de Agamenón o de Aquiles, mencionados por este filósofo alemán del siglo XVIII (Lessing, 2002, pp. 151-157). 
El ánimo del objeto parlante, en este poema, contrasta con el de los poemas anteriormente analizados: mientras que el rizo de Berenice (poema 66) se queja amargamente de haber sido separado de la cabeza de la reina, y la puerta (poema 67) trata angustiosamente de defender su dignidad como guardiana de la casa a la que pertenece, el barco del poema 4 está satisfecho de su vida, de los viajes que ha emprendido junto a su dueño -a veces peligrosos, pero siempre conducidos a buen término-, y de su próxima consagración a los Dióscuros, dioses tutelares de la navegación.

\title{
2. La enunciación de objeto en Horacio
}

La "Sátira I, 8" de Horacio, se sitúa en el antiguo cementerio de las Esquilias, el cual, en el presente de la enunciación del poema, ha sido transformado en jardín por intervención de Mecenas. En este contexto, una estatua de madera del dios Príapo sirve de espantapájaros de ladrones y hechiceras:

\begin{abstract}
Hace tiempo yo era un tronco de higuera, madera inútil, hasta que un artífice se fijó en mí, preguntándose si debería convertirme en banco o dios. Se decidió por lo segundo, y desde entonces soy un dios, el más terrible espantajo de aves y ladrones; a éstos los intimido con mi diestra y el palo rojo que se levanta obscenamente de la base de mis ingles; en cuanto a las aves importunas, una caña clavada en el vértice de mi cabeza las aterra y les impide hacer daño en los huertos recién plantados (Horacio, 2001, p. 95).
\end{abstract}

Este Príapo de madera expresa su desagrado por los rituales que llevan a cabo en el jardín dos hechiceras, Canidia y Sagana. Pero la estatua no se limita a expresar esta queja, sino que también procede a relatar en primera persona las acciones que ha tomado para poner en fuga a las mujeres: “¿cómo, al fin, me vengué del horror que sentí siendo testigo de las voces y los hechos de las dos Furias? Pues hice salir un pedo de mis nalgas de higuera, que resonó tanto como la explosión de una vejiga" (Horacio, 2001, p. 97). Así, la estatua, hastiada de las hechiceras, recurre a un gesto chabacano (y muy humano) para ahuyentar a estos personajes, quienes, irónicamente, mediante sus sortilegios, se consideraban capaces de controlar la Naturaleza, las fuerzas sobrenaturales y el comportamiento humano. La prosopopeya del objeto inanimado, en el presente texto, a diferencia de los casos estudiados hasta ahora, no se circunscribe simplemente a la posibilidad de ofrecer un pensamiento y de expresarlo lingüísticamente, sino que también se amplía a una actividad fisiológica (recordemos, en este sentido, el carácter antropomorfo de los dioses grecolatinos).

No ha de extrañar el regular uso que los escritores han hecho, en la historia literaria occidental, de las estatuas parlantes o pensantes: por su carácter figurativo, otorgan un mayor grado de verosimilitud a la enunciación de objeto. En el caso del Príapo horaciano, la escultura no solo habla, sino que incluso se comporta como un ser humano. Desde el pensamiento animista se considera que la representación figurativa (pinturas, esculturas) alberga vida. La potencialidad animista de las estatuas ha sido un tópico cultural, desde la Antigüedad, en multitud de relatos (religiosos y no religiosos), como ha destacado David Freedberg en su libro El poder de las imágenes (2009). Frente a las innumerables narraciones sobre el deseo que despiertan las figuras o figuraciones humanas de esculturas y pinturas, representaciones que sus espectadores contemplan como si estuvieran dotadas de vida, la enunciación de objeto que otorga voz a una escultura o a una pintura se pone del otro lado del campo de batalla para responder a la pregunta: ¿Qué tal si las esculturas o pinturas que parecen estar dotadas de vida 
no solo la tuvieran, sino que además, contaran con la posibilidad de reflexionar, de opinar, de hablar y de ofrecer su propio punto de vista sobre la realidad humana? ${ }^{3}$

La "Sátira I, 8" no nos ofrece la única estatua pensante / parlante de la historia de la cultura occidental. Son numerosos los ejemplos. Sin ir más lejos, y como caso contemporáneo, podemos aludir a la canción "La estatua del jardín botánico" (1982), escrita por Santiago Auserón, del grupo español de rock Radio Futura. La letra está enunciada en primera persona por una estatua de metal situada en un arcaico jardín de estatuas de piedra: "Soy metálico en el Jardín Botánico. / Con mi pensamiento sigo el movimiento / de los peces en el agua”.

\section{La enunciación de objeto en Marcial}

Una de las primeras manifestaciones literarias en la cultura grecolatina fue la de los epigramas. En Roma, Marco Valerio Marcial fue el autor más destacado en este género. Dos de sus obras, Xenia (Libro XIII) y Apophoreta (Libro XIV) contienen epigramas en dísticos elegíacos; se trata de 'literatura de ocasión', pues ambos fueron compuestos por el poeta para acompañar los regalos que se intercambiaban en las Saturnales (Marcial, 1997, p. 321, notas de Fernández Valverde y Ramírez de Verger). En todo caso, como expresa Muñoz Jiménez (1996, p. 138), se puede establecer una subdivisión interna en estos epigramas:

Cada librito cuenta con una especialización en el tema, al tratar Xenia exclusivamente de productos 'perecederos'

-comestibles y bebidas-, mientras que Apophoreta ofrece una descripción variada de muy diversos objetos; de esta manera las dos obritas se oponen (Xenia: 'perecederos'/ Apophoreta: 'no perecederos') (en cursiva en el original).

En muchos de los dísticos de estos libros se emplea la voz objetual. Como muestra, entre los regalos comestibles está el representado en el libro XIII, epigrama 50: "Las trufas, que con nuestra tierna cabeza rompemos la tierra / nutricia, somos los frutos que van detrás de las setas" (Marcial, 1997). Es decir, en términos de preferencia de los comensales, las trufas se encuentran en segundo lugar, después de las setas.

Como se dijo, los regalos también podían consistir en objetos no perecederos. Por ejemplo, Marcial pone en boca de una lámpara (libro XIV, epigrama 39) el siguiente enunciado: "Yo, una lámpara testigo de las dulzuras de tu cama, / aunque hagas todo lo que quieras, guardaré silencio" (Marcial, 1997). Este objeto cumple con la misma función de 'testigo indiscreto' que asumía la puerta en el Poema 67 de Catulo. En el libro XIV, epigrama 44 también es protagonista una lámpara, que declara: "Ves que soy de madera; si no vigilas las llamas, / se te formará con tu candelabro una inmensa lámpara" (Marcial, 1997). El objeto en este poema expresa de manera humorística una advertencia a su nuevo dueño: debe estar vigilante para que la lámpara no se incendie. En otra instancia, una siringa interpela al destinatario del obsequio: “PPor qué te ríes de que yo esté formada con cera y caña? / La flauta

3 El poeta romano Ovidio relata en sus Metamorfosis (2003, vv. 243-297) la historia del escultor Pigmalión, quien se enamoró de su creación, una estatua femenina a la que llamó Galatea. Esta escultura, mientras fue una representación figurativa artística, nunca dio manifestaciones de vida interior, por más que se asemejara a una mujer de carne y hueso y que su creador anhelara correspondencia en el amor que le profesaba: "El rostro es de una auténtica doncella, pensarías que vive y, si no lo impidiera el pudor, que quiere moverse: hasta tal punto el arte se oculta en su propio arte. Pigmalión la admira y hunde en su pecho un fuego por un cuerpo fingido" (vv. 250-253). Solo cuando se convirtió en mujer, por don divino, pudo interactuar - comunicarse- con Pigmalión (vv. 290-294). 
de Pan que se hizo la primera vez era así” (libro XIV, epigrama 64). Alude esta flauta al mito etiológico protagonizado por la náyade Siringe, recogido por Ovidio en sus Metamorfosis (2003, vv. 689-712). En esta historia, Siringe era objeto de las 'atenciones' indeseadas del dios Pan y era perseguida por él. En su huida se vio obstaculizada por un río y suplicó a las ninfas de las aguas, en estas circunstancias, que la ayudaran a escapar. Pan, al tratar de abrazar a la doncella, la descubrió transformada en cañas de pantano. En ese momento, escuchó una suave melodía, producida por el soplo del viento entre las cañas. "El dios, cautivado por este nuevo arte y la dulzura de la voz, había dicho: 'Este diálogo habrá siempre entre tú y yo', y así, unidas las cañas dispares con una ensambladura de cera, conservó en ellas el nombre de la doncella" (2003, vv. 709-712).

Una muestra más de enunciación de objeto la constituye otra lámpara, esta vez no de alcoba, sino de salón de banquetes (libro XIV, epigrama 41): "Aunque ilumino con mi resplandor banquetes enteros / y sostengo tantos candelabros, se me llama una sola lámpara" (Marcial, 1997). Se atisba en este último caso cierta queja del objeto -que pretende reivindicarse- ante la indiferencia que recibe de los seres humanos.

En palabras de Muñoz Jiménez (1996, p. 140), Marcial logra resaltar con estos epigramas los actos pequeños de la vida cotidiana mediante la ubicación de diversos objetos en su contexto concreto. Además, tanto las primeras lámparas como la siringa sirven de vehículo al humor por el que este escritor es reconocido.

Entre los epigramas, “destacan los epigramas funerarios o epitafios, consistentes en su origen en breves composiciones versificadas sobre las tumbas, que indican filiación, edad y alguna característica destacada del difunto" (Hualde Pascual, 1995, p. 73). En los epitafios, tanto literarios como no literarios, muchas veces el muerto emite su discurso en primera persona, como el del siguiente soldado romano. Si bien quien habla, en última instancia, es un ser humano (difunto, en este caso), en el mundo fenomenológico es el soporte objetual el que se expresa: "Soy Tito Cesonio, hijo de Quinto, del distrito electoral Sergiano, veterano de la Quinta Legión Gala. Durante mi vida bebí sin freno. ¡Vosotros que aún vivís, bebed!” (Díaz, 2013, párr. 7). La función del presente epitafio, aparte de dar información sobre el ocupante de la tumba, es la de expresar el tópico del carpe diem ${ }^{4}$ : ¿quién mejor que un difunto puede dar fe de la brevedad de la vida y aleccionar a los vivos a aprovecharla al máximo?

El ejemplo más famoso de epitafio, en todo caso, procede de una pintura barroca cuya escena se encuentra ubicada en una Antigüedad atemporal. Se trata del cuadro Et in Arcadia Ego (Yo también estuve -o estoy-en Arcadia), de Nicolás Poussin, donde unos pastores supuestamente alfabetizados, en el mundo idealizado en el que viven- leen un enunciado en una inscripción funeraria, el mismo que da título al cuadro. En opinión de W. J. T. Mitchell (2009, pp. 73-74), este enunciado es ambiguo: "el «Yo» puede ser un pastor muerto que habla desde el pasado, o la Muerte misma, que habla ominosa en el presente eterno". Cuvardic (2017, p. 98) explica estas posibilidades de lectura:

En una primera lectura, y desde el empleo del verbo en pasado, puede querer decir: 'Yo, que fui pastor y ahora soy un ser fallecido, también estuve en Arcadia, como ustedes, pastores vivos. Tarde o temprano, ustedes estarán muertos y hablarán desde el mismo lugar enunciativo que yo utilizo en estos momentos.' Esta primera lectura también se manifiesta en una de las voces difuntas de la poesía lírica, claramente ficcionalizada, aquella que caracteriza a la poesía de los epitafios, donde el sujeto ya fallecido interpela al caminante para que detenga su camino, lea el

$4 \quad$ Invitación a disfrutar del presente sin preocuparse del futuro. 
enunciado, y reflexione sobre la condición mortal de todo ser humano. En una segunda lectura del cuadro de Poussin, donde el sujeto enunciativo es la Muerte, se emplea el verbo en presente: "Yo -Muerte- también estoy en Arcadia. Aunque ustedes consideran el placer que disfrutan como eterno, les aviso que en cualquier momento puedo terminar con su vida"5.

Ya en el plano literario, en la obra de Marcial se encuentran varios epitafios, como el V, 34, el V, 37 y el X, 61, dedicados a la niña Eroción, o el VII, 96, en honor al niño Úrbico:

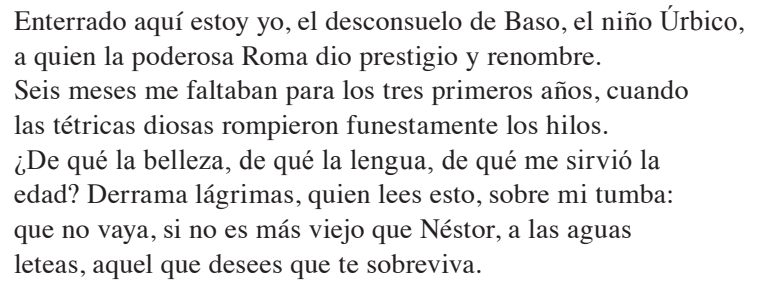

Apunta Hualde Pascual (1995, p. 74) que los epitafios dedicados a la muerte de niños (que provocan mayor compasión debido a la corta edad del difunto), como los compuestos por Marcial, han dado origen a tópicos literarios cuya pervivencia se atestigua en la tradición humanística. Entre ellos se encuentra el de la cuna vacía, muy presente en el Posromanticismo (Cuvardic, 2015). En estos poemas, a pesar de que el enunciador es, estrictamente, un ser humano, el mensaje "emitido" por el difunto no podría ser recibido por los vivos sin la intermediación del soporte material. Si bien no estamos en presencia, en sentido estricto, de una enunciación de objeto, pues la tumba o lápida no transmite sus propios pensamientos o percepciones, tampoco se puede afirmar que sea una persona quien toma la voz. El epitafio en primera persona es un caso límite en nuestro objeto de estudio.

Los enunciados expresados en los epigramas de los libros XIII y XIV de Marcial han de ponerse en relación con los numerosos casos de objetos artísticos que, desde la Antigüedad grecolatina -pasando por la Edad Media, el Renacimiento y el Barroco, hasta desembocar en los siglos XVIII; XIX y XX- incorporan enunciados expresados en primera persona del singular (excepcionalmente, del plural), donde se menciona y se ponen en relación el artesano que lo ha fabricado, el objeto, el propietario y su uso o función. Bredekamp (1917, pp. 41-65) analiza numerosos ejemplos, que vamos a mencionar ya traducidos al español: en la Fíbula de Palestrina -la fíbula es una prensa para una túnica- aparece la siguiente inscripción: "Mario me hizo para Numerio". Es una etiqueta por la que el fabricante señala el usuario y propietario de la pieza que fabricó. Otros ejemplos son: "Yo soy de Tharios", de un vaso griego (ca. 650 a. C.), donde se nombra al propietario; "Salúdame y bebe de mí, ¡verdaderamente!", de una copa ática (mediados del siglo VI a. C.), que alude a su función práctica, la de ser contenedor para la bebida; "Mantiklos me ha ofrecido, del diezmo de sus ingresos, a aquel que, con el arco de plata, acierta a gran distancia", del Apolo de Mantiklos (siglo VII a. C.), que expresa su condición de trofeo de una competición; o "Soy un cuenco para contener alimentos", del Baptisterio de San Luis en Damasco (entre 1340 y 1350), donde de nuevo se muestra la función para la que fue elaborado, la de ser un utensilio de comida, en una tradición que pervivirá a lo largo de la Edad Media y más allá. En la Antigüedad, era común que los objetos y las obras de arte hablaran en las inscripciones de estas últimas, y la literatura grecolatina no deja de recoger

5 Paul de Man, el famoso teórico y crítico del Romanticismo, utiliza estos epitafios como símbolo de la ficcionalidad de toda autobiografía en su conocido artículo "La autobiografía como des-figuración" (2007). 
esta práctica, común en estas culturas, en epigramas y poemas. Es decir, la literatura se ocupa de describir objetos (formas icónicas, al fin y al cabo) que 'emiten' actos de habla verbales en inscripciones y textos de diverso tipo.

\section{Conclusiones}

La tendencia del ser humano a otorgar vida y atributos humanos al mundo objetual es tan antigua como la humanidad. Desde la prehistoria, las personas han manipulado piedras y meteoritos para otorgarles atributos antropomorfos. Asimismo, en los relatos tradicionales del folclore universal más antiguo se alude a entidades de la naturaleza y objetos manufacturados que cuentan con estas últimas cualidades. Es una práctica que responde al pensamiento animista, enraizado en el inconsciente del ser humano. La literatura grecolatina, en este sentido, también incorpora procedimientos de personificación de objetos y entidades naturales, los cuales actúan mediante la comunicación oral, dotados de la facultad del habla. Cabe resaltar que estos objetos carecen de movilidad independiente y su acción se circunscribe al acto de enunciar. En algunos poemas de Catulo (4, 66 y 67), así como en varios epigramas de Marcial (contenidos en los libros XIII y XIV de su obra) y en la "Sátira I, 8" de Horacio, se puede identificar esta enunciación de objeto, del mismo modo que en casos aislados procedentes de Homero (Ilíada) y Apolonio de Rodas (Argonáuticas).

Además de ofrecer una perspectiva novedosa del acontecer humano, la función expresiva de la enunciación de objeto es variada. En algunos casos, está presente la comicidad: la puerta del poema 67 de Catulo resulta ridícula en su intento por defender su dignidad como guardiana del hogar y más bien se revela como traidora de los secretos familiares. Asimismo, Horacio utiliza la comicidad del comportamiento de la estatua de Príapo para ridiculizar y desvalorizar las acciones, en su opinión despreciables, de las dos hechiceras que frecuentaban el cementerio para realizar sus rituales. Por su parte, en los poemas 4 y 66 de Catulo no se distingue este tono cómico; en el primero, el barquito que hace un recuento de su vida se ve revestido de dignidad y satisfacción por las experiencias pasadas y, en el 66, el rizo de Berenice expresa su angustia por verse separado contra su voluntad de su querida ama. En el caso de Marcial, los objetos y alimentos que toman la palabra en los epigramas abren una pequeña ventana hacia la vida cotidiana de los romanos del siglo I d. C..

Ha de diferenciarse la enunciación de objeto en la cultura grecolatina (en la que el objeto evalúa, desde su propia subjetividad, su propia singularidad y su relación con la sociedad), de la fábula (donde animales y objetos son transposiciones alegóricas de la conducta humana), y del relato maravilloso de objetos parlantes, donde las cosas cumplen el papel de auxiliares mágicos, en terminología de Vladimir Propp. La enunciación de objeto que hemos analizado en Catulo, Horacio y Marcial no tiene carácter alegórico.

La enunciación de objeto en la cultura grecolatina se ha de considerar como precedente o precursora de la it-fiction satírica de la literatura occidental de los siglos XVIII y XIX. ¿Por qué motivos? En primer lugar, por su carácter satírico. En el género de la it-fiction, a través de los objetos se satirizan las costumbres, los vicios y los defectos humanos que involucran muchas veces la codicia. De igual manera ocurre en el caso de la estatua del poema de Horacio, la cual hace burla de los rituales que llevan a cabo dos hechiceras. En el poema 67 de Catulo, el carácter satírico se manifiesta por medio de la ironía de la puerta que, deseando defender su buena reputación como custodia de la virtud de su hogar, más bien se revela como una chismosa, 
dando a conocer los secretos amorosos de los habitantes de su casa. De esa manera, pone en evidencia -involuntariamente- la ausencia de virtud de dichas personas. Por su parte, en algunos epigramas de Marcial es evidente la presencia del ingenio y humor tan característicos de este autor, aunque no llegan al tono satírico.

En segundo lugar, tanto en la it-fiction como en sus precursores romanos, el objeto siempre se relaciona con el ser humano, en diferentes grados de cercanía material y afectiva. La relación objeto-humano es explicada, en ambos casos, por la primera entidad. Se ofrece el punto de vista de la 'cosa', en un contacto que pasa, ante todo, por la relación de posesión. El perspectivismo que apreciamos en los textos romanos estudiados es un precedente de la literatura satírica de los siglos XVIII y XIX.

En tercer lugar, en ambas manifestaciones literarias los objetos cumplen con la función focalizadora, al ser testigos de las acciones humanas. Tanto en la it-fiction como en la literatura romana, los objetos están presentes en el quehacer humano: desde la ofrenda a los dioses en un palacio real hasta la donación de los regalos intercambiados entre amigos. La presencia, la observación y la voz de los objetos nos hace partícipes de las actividades emprendidas por sus dueños en contextos cotidianos y realistas. Ya no hablamos de una enunciación objetual situada en contextos maravillosos o fantásticos.

En los ejemplos de literatura romana mencionados, se emplea la convención narrativa, típica de la posterior it-fiction, mediante la cual el objeto se queja ante los lectores de ser una simple 'entidad' sin la voluntad o la capacidad 'motriz' suficiente como para contrarrestar las decisiones del ser humano. En este sentido, contamos con una excepción: la estatua de Príapo -tal vez por ser representación de un dios- en cierta medida posee la capacidad de influir en el comportamiento de quienes la rodean. El Príapo de madera siente un profundo desprecio por las hechiceras que frecuentan sus cercanías y logra librarse de ellas mediante un recurso típicamente humano.

Cabe aclarar que la enunciación de objeto en los autores romanos analizados, al contrario de la it-fiction, no constituye un género literario independiente, sino que se trata, más bien, de un procedimiento retórico y enunciativo enmarcado dentro de diversos géneros: la poesía lírica, en Catulo, la sátira, en Horacio y el epigrama, en Marcial.

\section{Bibliografía}

Apuleyo. (1970). El asno de oro. Barcelona: Bruguera.

Blackwell, M. (Ed.). (2007). The Secret Life of Things. Animals, Objects, and It-Narratives in Eighteenth-Century England. Lewisburg: Bucknell University Press.

Bredekamp, H. (1917). Teoría del acto icónico. Madrid: Akal.

Calímaco. (1980). Himnos, epigramas y fragmentos. Madrid: Gredos.

Canter, H. V. (1920). The Paraclausithyron as a Literary Theme. The American Journal of Philology, 41(4), 355-368.

Catulo. (2003). Poesías. Introducción, traducción y comentario de Antonio Ramírez de Verger. Madrid: Alianza Editorial.

Catulo. (2006). Poesías. Edición bilingüe de José Carlos Fernández Corte. (J. A. González Iglesias, trad.). Madrid: Cátedra. 
Cuvardic García, D. (2015). El motivo de la cuna vacía en la poesía lírica posromántica española. Revista de Filología y Lingüística de la Universidad de Costa Rica, 41(1), 11-29.

Cuvardic García, D. (2017). La voz enunciativa del sujeto difunto frente al mundo de los vivos en El año del laberinto de Tatiana Lobo. En La fiesta, el duelo y el horror: Representaciones de la muerte en la literatura latinoamericana. Seguin, Texas: Chiringa Press.

De Cirene, E. (1999). Mitología del firmamento (Catasterismos). Madrid: Alianza Editorial.

De Man, P. (2007). La autobiografía como des-figuración. En La retórica del Romanticismo (pp. 147-158) Madrid: Akal.

De Rodas, A. (1996). Argonáuticas. Madrid: Gredos.

Díaz, Laura. (2013). Epitafios romanos. Recuperado de http://losfuegosdevesta.blogspot. com/2013/01/epitafios-romanos.html

Fernández Corte, J. C. (2006). Introducción y Notas. En Catulo Poesías (pp. 9-181 y 505-785). Madrid: Cátedra.

Freedberg, D. (2009). El poder de las imágenes (2 ed.). Madrid: Cátedra.

Homero. (1991). Ilíada. Madrid: Gredos.

Horacio. (2001). Sátiras. (Introducción, Traducción y notas de Jerónides Lozano Rodríguez). Madrid: Alianza Editorial.

Hualde Pascual, M. (1995). Epitafios infantiles: una tradición grecolatina en la literatura inglesa. Epos: Revista de Filología, 11, 73-84.

Lessing, G. E. (2002). Laocoonte o sobre los límites en la pintura y la poesía. Barcelona: Folio.

Marcial. (1997). Epigramas. Vol. I y II. (Traducción y notas: Juan Fernández Valverde y Antonio Ramírez de Verger). Madrid: Gredos.

Mitchell, W. J. T. (2009). Teoría de la imagen. Madrid: Akal.

Mortara Garavelli, B. (2000). Manual de retórica. Madrid: Cátedra.

Muñoz Jiménez, M. J. (1996). Rasgos comunes y estructura particular de Xenia y Apophoreta. Cuadernos de Filología Clásica. Estudios Latinos, 10, 135-146.

Ovidio. (2003). Metamorfosis. Madrid: Alianza Editorial.

Peiré Santas, P. y Puyuelo Ortiz, E. (2002). Algunos tópicos clásicos en un soneto de Lupercio Leonardo de Argensola. En J. M. Maestre Maestre, J. Pascual Barea, L. Charlo Brea (Eds.), Humanismo y pervivencia del mundo clásico: Homenaje al profesor Antonio Fontán. III, Volumen 4 (pp. 1969-1978). Madrid: Editorial CSIC - CSIC Press.

Peñas Ruiz, A. (2011). Márgenes del costumbrismo en Las ferias de Madrid (1845) de Neira de Mosquera. En A. L. Baquero Escudero, F. Carmona Fernández, M. Martínez Arnaldos, A. Martínez Pérez (Eds.), La interconexión genérica en la tradición narrativa (pp. 159-183). Murcia: EDITUR.

Peñas Ruiz, A. (2012). La circulación de formas y técnicas narrativas: sobre it-fiction y cuento de objeto. En L. Silvestri, L. Frattale y M. Lefèvre (Eds.), Rumbos del hispanismo en el umbral del Cincuentenario de la AIH. Vol. V, Moderna y Contemporánea (pp. 497508). Roma: Bagatto Libri. 
Peñas Ruiz, A. (2017). Miradas de lo insignificante: de la it-fiction a las nuevas formas de hacer historia. En J. M. González Herrán, M. L. Sotelo Vázquez, M. C. Carbonell, H. Gold, D. Thion Soriano-Mollá, B. Ripoll Sintes y J. Cáliz Montes (Eds.), La historia en la literatura del siglo XIX (Sociedad de Literatura del Siglo XIX) (pp. 473-492). Barcelona: Edicions de la Universitat de Barcelona.

Propp, V. (1985). Morfología del cuento. Madrid: Akal Editorial.

Radio Futura. (1982). La estatua del jardín botánico. Sencillo. Madrid, España: Hispavox. 
